\title{
Emerging Value Propositions for M-commerce
}

\author{
Irvine Clarke III \\ James Madison University $\bullet$ Harrisonburg, VA
}

\section{Abstract}

The proliferation of mobile Internet devices is creating an unparalleled opportunity for e-commerce to leverage the benefits of mobility. Mobile e-commerce, commonly referred to as $\mathrm{m}$-commerce, is the ability to purchase goods anywhere through a wireless Internet-enabled device. Current e-commerce providers, engaged through mobile devices, will find advantage in developing unique m-commerce value propositions founded upon the specific dimensions of ubiquity, convenience, localization, and personalization. A consumer orientation that provides value-fortime functions to create a new value curve may achieve a competitive advantage over traditional e-commerce models replicated for mobile business. Therefore, this paper investigates the value propositions, that engender a productive mobile e-commerce strategy to provide recommendations for managerial decision-making in this emerging wireless environment.

\section{Introduction}

In the new decade, the call for information technology will be information, any time, any place and on any device. Accordingly, e-commerce is poised to witness an unprecedented explosion of mobility, creating a new domain of mobile commerce. Mobile commerce, or m-commerce, is the ability to purchase goods anywhere through a wireless Internet-enabled device. Mobile commerce refers to any transaction with monetary value that is conducted via a mobile network. It will allow users to purchase products over the Internet without the use of a PC. "Within five years, individual e-commerce services will be primarily delivered by wireless and the wireless terminal will become the window of choice to the transactional e-world," says Neil Montefiore, executive of Singapore mobile operator M1 (Hoffman, 2000, p.20). This proliferation of wireless capability has created an emerging opportunity for e-commerce businesses to expand beyond the traditional limitations of the fixed-line personal computer.

The magnitude of the mobile Internet revolution will pressure current ecommerce business models, create apertures for new mobile Internet companies, engender a stream of change among established e-commerce paradigms, and lead to a reconfiguration of value propositions in many industries (Evans \& Wurster, 1997). However, m-commerce is still not without its limitations. The problems it must 
overcome include: uniform standards, ease of operation, security for transactions, minimum screen size, display type and bandwidth, billing services, and the relatively impoverished web sites. Due to current technological limitations, limited service availability, and varying mobile consumer behavior patterns, business strategies developed for $\mathrm{m}$-commerce applications will find it necessary to emphasize differing characteristics than traditional e-commerce strategies (Barnett, Hodges \& Wilshire, 2000; Datamonitor, 2000). Successful m-commerce providers will understand that consumers are unwilling to spend long periods "surfing" on these inherently less user-friendly wireless devices (Albright, 2000). Wireless users demand packets of hyper-personalized information, not scaled-down versions of generic information. Therefore, technology-focused wireless Internet business models will be replaced by models which best integrate the unique characteristics of wireless $\mathrm{m}$-commerce. As such, the long-term success of e-commerce may be partially dependent upon the successful development of effective consumer-oriented m-commerce business strategies. "Mobile commerce is per se not included in the traditional e-commerce market models. M-commerce will be able to increase the overall market for e-commerce, because of its unique value proposition of providing easily personalized, local goods and services anytime and anywhere" (Durlacher, 2000, p. 12).

Despite tremendous interest in the melioration of m-commerce there is little, if any, research that examines how to develop a comprehensive consumer-oriented mobile e-commerce strategy. Therefore, the primary purpose of this paper is to explore the factors which compose an effective m-commerce strategy. First, this paper investigates the nonpareil benefits of mobile applications. Then, this paper explores how managers can incorporate potential m-commerce value propositions into their overall e-commerce strategies through creating new market space (Kim \& Mauborgne, 1999). Given the potential assemblage of wireless Internet devices, an enhanced understanding of m-commerce could acutely improve a company's overall ability in e-business strategy formulation.

\section{Background}

Mobile devices have been the fastest adopted consumer products of all time with, last year, more mobile phones shipped than automobiles and PCs combined (Chen, 2000; de Haan, 2000). By 2003, there will be 1.4 billion mobile phones worldwide and half will be Internet-enabled (Zabala, 2000). Nokia estimates that by 2002 a greater number of people will be linked to the Internet via wireless connections than through traditional fixed lines (Daitch, Kamath, Kapoor, Nemiccolo, Sahni \& 
Varma, 2000). ${ }^{1}$ Fueled by such enabling technologies as $3 \mathrm{G}$ broadband capability, eXtensible Markup Language (XML), Compact HTML (CHTML), Wireless Markup Language (WML), Wireless Application Protocol (WAP), General Packet Radio Services (GPRS) and Internet ready mobile terminals, e-commerce is now poised to take advantage of the current growth of mobile devices. "The wireless world is a parallel universe almost as large as the Net, and the two are beginning a fascinating convergence," said Swapnil Shah, director of Inktomi Europe, a search engine and caching solutions company (Rao, 2000).

However, U.S. providers have lagged in m-commerce development since the U.S. market has been PC oriented for Internet technology. The U.S. leads the world in almost every e-commerce metric, while Europe and Japan have taken early leads in $\mathrm{m}$-commerce. In fact some countries in Europe, like Spain and Italy, may completely leap PC-oriented e-commerce, based on their veneration of mobile phones, directly to m-commerce. As many as 100 new m-commerce companies launch in Europe each month (Brandt, 2000). Telefonica Italy is already selling all cellular phones with a pre configuration for Internet access. In Japan, mobile phones penetrate about $50 \%$ of the market with NTT DoCoMo's internet enabled $i$-mode service already connecting more than 5 million wireless users to the web. These markets continue to grow in appeal as DoCoMo's i-mode is attracting about 12,600 new users per day, each generating about $\$ 26 /$ month in additional revenue per user (Schenker, 2000).

Commerce transpires as organizations introduce new methods to employ mobile devices to communicate, inform, transact and entertain using text and data via connection to public and private networks. This emergence of mobile commerce will happen even faster than the development of e-commerce - in roughly the time between the invention of the first Web browser and now (Schenker, 2000). "If you look five to 10 years out, almost all of e-commerce will be on wireless devices," says Jeff Bezos chief executive and founder of Amazon.com (McGinity, 2000). Consequently, within the next 5-years, one-quarter of all electronic commerce will take place through wireless devices (Zabala, 2000). Forecasts estimate the wireless web to be as large as the wired web of today and worldwide mobile commerce exceeding $\$ 200$ billion by 2004 (M-commerce Times, 2000; Shaffer, 2000).

The potential of $\mathrm{m}$-commerce is considerable for those willing to develop mobile-specific business strategies. As m-commerce matures, current mobile operators will rely less upon usage fees and increasingly derive revenues from content and services (Datamonitor, 2000; KPMG, 2000). Additionally, m-commerce is going to bring about a massive change in the way users consume products and services. 
"It is key that commerce companies recognize m-commerce as a completely unique service. Cell phone users are more impatient than Internet users. The paradigm here is not surfing; all services for the mass market have to be pitched at users in such a seamless way that they need not even be aware that they are accessing the net."

Cindy Dahm, European director for Phone.com

(Rao, 2000, p.2).

Those best able to provide value-added user experiences, through content aggregation and portal development, will achieve long-term success. Merely extending the current Internet presence will not be enough. "Mobile internet customers will be more demanding. They will want personalized service to meet their individual wants and needs and will no longer be satisfied with being a mass market" (KPMG, 2000, p. 2). Providers must take advantage of the characteristics which make m-commerce distinct from e-commerce to develop truly unique and compelling services rather than replicating current e-commerce models. Current e-commerce strategy is based on a traditional paradigm of consumers as passive receivers of communication efforts with the service provider holding control of the "when" and "where" of information (Mahadevan, 2000). With wireless internet enabled devices, consumers now have more discretion of "when" and "where" the information that is available, creating new market space and demand for a specialized mobile business offering.

\section{Value Propositions for $\mathrm{m}$-Commerce}

Value propositions define the relationship between supplier offerings and consumer purchases by identifying how the supplier fulfills the customer's needs across different consumer roles (Band, 2000; Porter, 1998). Specifically, it specifies the interdependence between the performance attributes of a product or service and the fulfillment of needs. The value proposition furthermore solidifies the relationship between the customer and various dimensions of product value. Thus, customer satisfaction is merely a response to the value proposition offered by a specific product/service bundle. For e-commerce, the establishment of a value proposition is rudimentary to any consumer-oriented strategy creation (Timmers, 1998).

The mobility afforded wireless devices shapes $\mathrm{m}$-commerce into a disparate entity from conventional e-commerce. Consequently, value propositions are likely to be new, different and novel for mobile e-commerce. The primary advantage of 
mobile devices is to provide a superior offering of value-for-time ${ }^{2}$ to users. That is, by accessing the Internet through mobile devices, users will be able to realize additional value allowances for any specified period of time, which fixed-line users will not be able to achieve. Information may now truly become available anytime, anyplace and on any wireless device. As such, value propositions of e-commerce will be forced to change to reflect the underlying dimensions of value-for-time for users (Figure 1). Specifically, m-commerce differs from e-commerce on the following value proposition attributes:

\section{Figure 1}

\section{Value Propositions of Mobile Commerce}

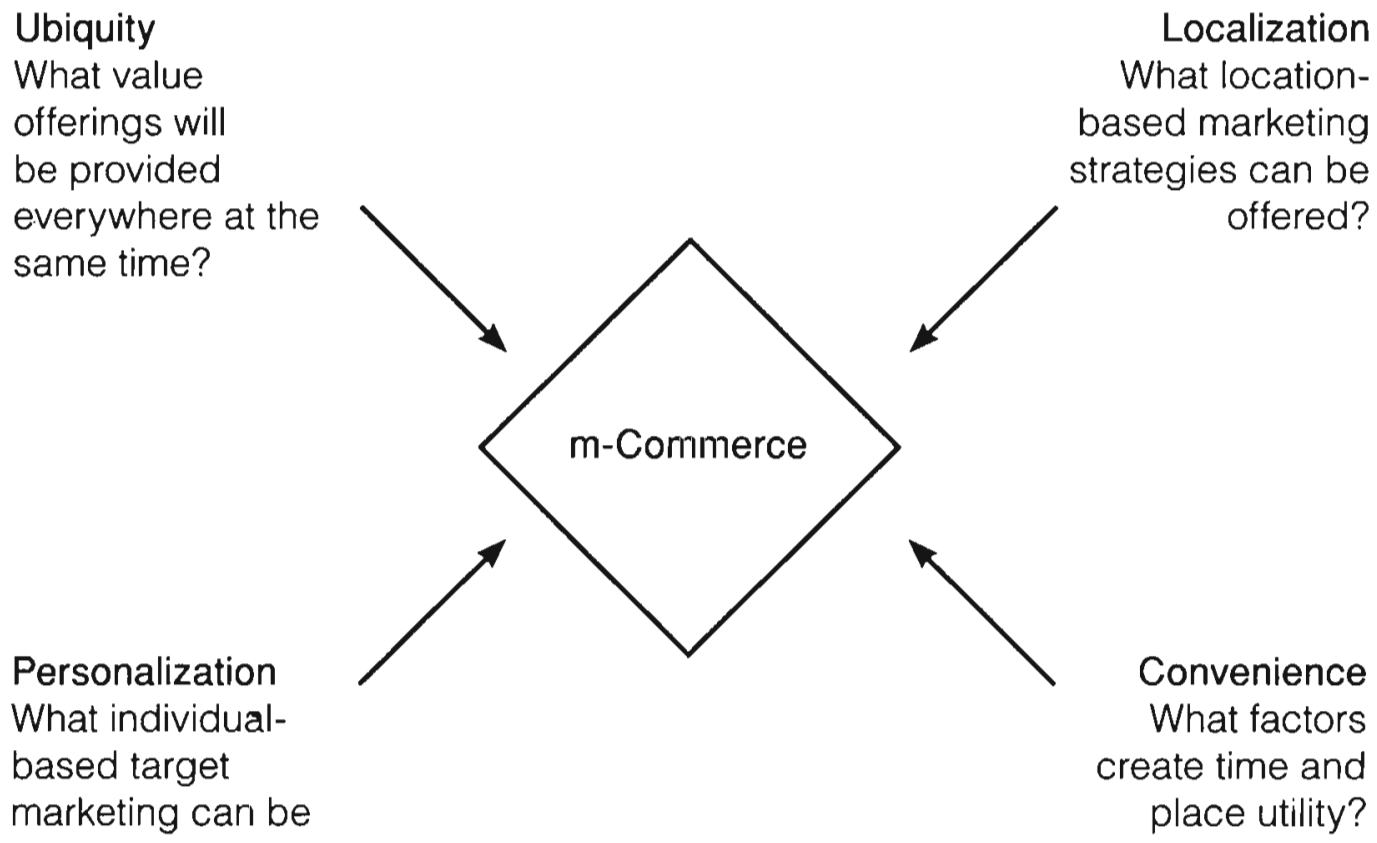

\section{Ubiquity}

Mobile devices offer users the ability to receive information and perform transactions from virtually any location on a real-time basis. M-commerce users will have a presence everywhere, or in many places simultaneously, with a similar level of access available through fixed-line technology. Communication can take place independent of the users location. The advantages presented from the omnipresence of information and continual access to commerce will be exceptionally important to time-critical applications. 
Mobile commerce businesses, for example, can leverage this value proposition by providing alert notifications, such as for auctions, betting, and stock price changes, which are specified by the user as an important part of relevant personal content. As such, the real-time, everywhere presence of $\mathrm{m}$-commerce will offer capabilities uniquely beneficial to users. Industries that are time and location sensitive, such as financial services and travel, are likely to benefit from businesses exploiting this value-added feature of mobile commerce.

\section{Convenience}

The agility and accessibility provided from wireless devices will further allow m-commerce to differentiate its abilities from e-commerce. People will no longer be constrained by time or place in accessing e-commerce activities. Rather, $\mathrm{m}$-commerce could be accessed in a manner which may eliminate some of the labor of life's activities. For example, consumers waiting in line or stuck in traffic will be able to pursue favorite Internet based activities or handle daily transactions through $\mathrm{m}$-commerce applications. Consumers may recognize a special comfort which could translate into an improved quality of life.

One opportunity to increase value lies in m-commerce capabilities that allow consumers to shop where they are not located. This ability to obtain information and conduct transactions from any location is inherently valuable to consumers. As such, $\mathrm{m}$-commerce offers tremendous opportunities to expand a client-base by providing value-added services to customers heretofore difficult to reach. By making services more convenient the customer may actually become more loyal. Consequently, communication facilities within m-commerce are key applications for the delivery of convenience. Consumers will be looking for $\mathrm{m}$-commerce applications which can deliver functions like: sending and receiving e-mail, voice mail forwarding, conference calling, faxing, document sharing, instant messaging; as well as transactional based activities.

\section{Localization}

Knowing the location of the Internet user creates a significant advantage for m-commerce over wired e-commerce. Location-based marketing, via global positioning technology, ${ }^{3}$ will soon be available in all mobile devices. Through GPS technology, service providers can accurately identify the location of the user. Utilizing this technology, m-commerce providers will be better able to receive and send information relative to a specific location. Since mobile devices like cell phones are 
almost always on, vendors will know the location of their customers and can deliver promotions based upon the likely consumer demands for that location. ${ }^{4}$

Location-specific information leverages the key value proposition of $\mathrm{m}$ commerce over traditional e-commerce by supplying information relevant to the current geographic position of the user. M-commerce providers will be able to both push and access information relevant to the users specific location. Mobile websites may serve as points of consolidation of consumer information and disseminate the relevant information for a particular location based on profile data built on the user's past behavior, situation, profile and location. As such, real time discounting may become the "killer application" for m-commerce. For example, each time you visit your local grocery store, Procter \& Gamble can send directly to your wireless device, through the designated mobile device, tailored promotional information on their products.

Advertising will also be profoundly influenced by the expansion of these wireless services. Mobile phones provide another effective medium for advertising products and services with the second highest potential reach, after television ( $\mathrm{Za}$ bala, 2000). Durlacher predicts that by the year 2003, advertising will be the leading mobile commerce application (Reed, 2000). Craig Owensby, COO of Spotcast says: "Mobile phone technologies are changing with incredible speed. Within two years, mobile phones will evolve into multimedia devices for m-commerce to offer personal video communications, receive customized information, access the Internet on-line [24 hours a day] to order and shop, as well as for games, entertainment and chatting. Soon advertising through a mobile phone will be as normal as advertising in newspaper or TV" (Zabala, 2000, p. 35). Applications based on this value proposition will expand the overall value frontier for mobile e-commerce as consumers recognize benefits from information relevant to the current geographic position.

\section{Personalization}

Mobile devices are typically used by a sole individual, making them ideal for individual-based target marketing. Mobile offers the opportunity to personalize messages to various segments, based upon time and location, by altering both sight and sound. New developments in information technology and data-mining make tailoring messages to individual consumers practical and cost-effective. For example, upon employing your mobile Internet device, advertising messages tailored to your individual preferences can be provided. Relevance of material, and the "de-massing" of marketing becomes possible through the personal ownership of 
mobile devices. "A wireless device is a very personal device. So it becomes increasingly important that the ads you deploy are value added," says Vic Vasan, Beyond Interactive Director of New Technology (Mack, 2000).

Additionally, personalized content is paramount in operating mobile devices because of the limitation of the user interface. Relevant information must always be only a single "click" away, since web access with any existing wireless device is not comparable to a PC screen either by size, resolution or "surfability." Therefore, subscriber profile ownerships is a key element in m-commerce success, as it will allow selectively targeted $\mathrm{m}$-commerce and advertising. As such, the mobile database becomes a primary factor of $\mathrm{m}$-commerce success by compiling personalized data bases and providing personalized services. One example, is the SIM (Subscriber Identification Module ${ }^{6}$ ) smartcards which serve as a mobile database allowing the user to run applications and operate secure transactions. Such personalized information and transaction feeds, via mobile devices, offer the greatest potential for the customization necessary for long-term success.

A value proposition is developed as superior consumer value is created through an increasingly targeted Internet experience for mobile users. For m-commerce, the technological limitations magnify these value-for-time propositions. It has been estimated that every additional click-through, which a user needs to make in navigating through a commercial online environment with a mobile device, reduces the possibility of a transaction by $50 \%$ (Durlacher Research, 2000). Providing the user with the desired, most relevant information without forcing a complex click-through sequence will significantly improve the effectiveness of any mobile ecommerce strategy. Value-for-time propositions become maximized for those business strategies best able to implement m-commerce's distinguishing capabilities. M-commerce businesses will become differentiated from traditional e-commerce based upon their abilities to integrate and actuate the advantages germane to mobile devices. Various applications may provide differing value for mobile Internet users (Figure 2).

Figure 2 illustrates some possible m-commerce applications which manifest the specified value propositions. Each application provides the user with value that cannot be found through traditional e-commerce. For example, a person who is waiting to check-out at the local grocery, and therefore is unable to access conventional e-commerce, may exercise this time to use their wireless PDA to: move monies between personal bank accounts (convenience), receive an e-mail reminder to pick-up their dry-cleaning (ubiquity), and watch a tailored promotion (personalization) for a product available at a nearby point-of-purchase display (localization). 
In the past, the time of queuing has eluded e-commerce providers, but now, mobile devices offer this same person greater access to valuable services.

Figure 2

m-Commerce Applications

\begin{tabular}{ll} 
Value Proposition & Application \\
\hline Ubiquity & - news \\
& - sports scores \\
& - track prices \\
- weather & - banking \\
- communication & - entertainment \\
- gaming & - mobile payment systems \\
& - retailing \\
& - videoconferencing \\
& - coupons \\
& - customer service \\
Localization & - dispatch/schedunting \\
& - emergency services \\
& - supply chain management \\
Personalization & - database development \\
& knowledge management systems
\end{tabular}

\section{Creating a New Value Curve}

E-commerce is becoming an increasingly competitive environment where value streams become the basis for business models and strategy development. Ecommerce strategies focusing on customer value - not on competition - may provide market opportunities in this hyper-competitive marketplace (Mahadevan, 2000). Yet, creating new market opportunities will require looking outside the accepted e-industry boundaries to unoccupied territory where breakthroughs in value can be discovered. This newly discovered market space can be represented by the value curve - a tool which visually represents a range of value propositions. All industries can be viewed as a collection of value offerings; the value curve is a tool 
used to differentiate the bundle of benefits offered to each market segment (Kim \& Mauborgne, 1997; Porter, 1998). The value curve is particularly useful to business managers, in that it creates a graphic depiction of the way an industry configures its offerings to customers (Kim \& Mauborgne, 1999).

M-commerce expands the horizons of value offerings to Internet users through its unique value propositions. However, the technological limitations of wireless devices also alters the overall value package provided to customers. Overall, wireless capabilities present the potential to advance the value curve creating new strategic opportunities for $\mathrm{m}$-commerce organizations. Figure 3 offers a comparison of the plausible value curves for both e-commerce and m-commerce. By integrating the value propositions into a new value curve, the area of market opportunity becomes apparent. The value curve shows the relative value of $\mathrm{m}$-commerce applications compared to more traditional e-commerce offerings.

\section{Figure 3}

\section{Value Curves for m-Commerce and e-Commerce Offerings}

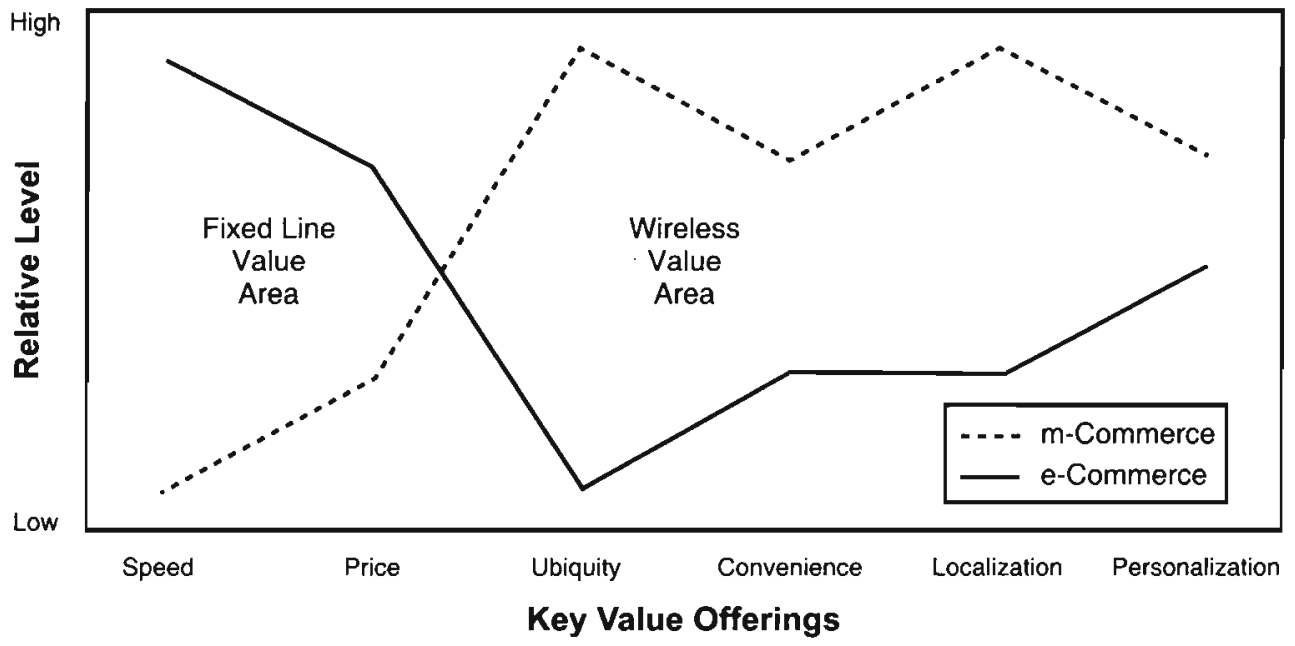

The dissimilarity of the curves illustrates the fundamental differences in overall value propositions. Clear advantages can be found for e-commerce in cost and speed. M-commerce provides for significant new value areas in ubiquity, localization, and convenience. Innovative companies can breach the e-commerce competitive environment by claiming the fundamentally new market space developed by the value propositions of mobility. Real value innovations are found in applications which emphasize the characteristics of the new m-commerce territory.

The m-commerce value curve depicts the relative advantages along key success factors. The broadened goal for $\mathrm{m}$-commerce companies is to offer more value 
to clients and end-user customers along the dimensions most relevant to each market segment. Ideally, m-commerce providers will take advantage of the opportunities germane to wireless devices to create product/service specific value curves which look preferable to traditional fixed-line PC-oriented e-commerce competition. By operating in this expanded frontier of value, fixed-line e-commerce competition will fail in attempts to replicate m-commerce value curves.

\section{Implications}

The emergence of $\mathrm{m}$-commerce specific value propositions has major implications in two different, but related ways. First, m-commerce will expose managers to a new consumer paradigm for decision making. Value-for-time will be derived from the factors of mobility. As such, managers who can expand the value frontier offered through leveraging the advantages of mobility will be able to provide superior value propositions, and potentially receive greater satisfaction from mobile consumers. The $\mathrm{m}$-commerce value frontier inherently expands the maximum performance currently feasible through ubiquity, convenience, localization, and personalization. Innovative market space is developed as managers devise applications to exploit this new area under the value curve. Second, the division of m-commerce strategies based upon consumer-orientation value propositions provides e-commerce researchers a tool for modeling the complex issues that are unparalleled in the mobile Internet.

\section{Business Implications}

Since the success of $\mathrm{m}$-commerce applications is dependent on the ease of use and the delivery of the appropriate information at the correct moment, valuefor-time propositions will be a key dynamic in determining the success of any $\mathrm{m}$ commerce business. Consumers utilizing wireless devices for Internet access will come to expect improved value from their wireless experience. Value-for-time will be accredited to those businesses which leverage the unique advantages of mobility. Increased value-for-time propositions will enhance the success factors of mobile e-commerce businesses, with rewards to providers in increased user acquisition and retention. The implications for managers failing to develop effective consumeroriented $\mathrm{m}$-commerce strategies may include: wasting company resources chasing the ever changing technological environment, consumer alienation, and erosion of e-commerce market share. Therefore, prudent managers may select to ask the following questions prior to offering an m-commerce application. 


\section{What is the value proposition provided from this wireless technology?}

Managers must identify the industry value frontier and define the key value propositions. In this instance, the value offered to consumers must be germane to the mobility advantages of m-commerce. If the same application can be provided through fixed lines, and provide the same utility to consumers, the long-term success prospects would be limited. This does not mean that a comparable service cannot be provided through competing platforms, rather that the mobile application should offer additional value over the fixed line applications.

\section{What market segments are best able to monetize this value proposition?}

Managers must select and define the most attractive value proposition for each consumer segment. Simple messages, based on the most relevant value offering, are likely to achieve greater success than broad-based, general appeals employing every possible value proposition. Accurate identification of the markets which could best utilize the benefits provided from a m-commerce strategy will improve the time frame for success. For example, consumers may use m-commerce based on lifestyle, segment application or professional use (KPMG, 2000). Astute managers will leverage m-commerce capabilities to develop specific mobile strategies which appeal to these likely user groups.

\section{Does this application have potential to become a "killer app"?}

Managers must always be aware that one application is likely to drive their segment of the m-commerce industry. The "killer app," or application which drives the development of that m-commerce sector, will likely vary across industries. ${ }^{8}$ Managers must utilize these specific functionalities as consumers will expect such service as norm in wireless Internet devices.

Is this value proposition congruent with other wireless applications currently provided?

Managers must find ways to organize and innovate to deliver the value proposition to consumers. Thus, it becomes ever important to recognize that applications do not exist in isolation..$^{9}$ In the wireless world, users have less control over the aggregation of the services provided than in the PC world. As such, it becomes 
imperative that managers are able to best identify the benefit provided and only offer new applications which fit the growing consumer-orientation.

\section{Research Implications}

The unprecedented growth in e-commerce has underscored the need for a better understanding of the successful mechanisms and business models. As new devices become available for Internet-based business, the development of new frameworks, specific to the mode of commerce will help researchers to better understand the complex environment of the digital world. The generic typology discussed in this paper will allow for a better understanding of the consumer benefits derived from making e-commerce mobile. Clearly the next step is to empirically test the relative value of these benefits to the overall success of the e-commerce business. Specific research questions are: Which value propositions are most highly related to profitability? Are there interactions amongst these value propositions? Which bundles of values are most attractive to various consumer segments? Are these value propositions relevant to all industries? Additionally, as m-commerce develops into a distinct discipline, detailed case studies can be developed to enhance our understanding and facilitate the implementation of successful m-commerce strategies.

\section{Conclusion}

"The wireless Web is truly the next major wave of Internet computing ... its potential for bringing people together and expanding commerce is even greater than that of the wired Internet."

Edward Kozel, board member

and former CTO of Cisco systems (AlterEgo, 2000, p.12)

E-businesses are currently being presented new mobile technologies for exercising the advantages of $\mathrm{m}$-commerce. E-commerce applications that succeed on the desktop PC win not necessarily meet with a similar accomplishment in a wireless commerce. Success will depend on the ability to integrate e-competencies of current business models with the unique features of $\mathrm{m}$-commerce. Long-term $\mathrm{m}$-commerce business success is likely to come from consumer-oriented, rather than technologybased strategies. Current e-commerce providers, engaged through mobile devices, will find advantage in developing unique $\mathrm{m}$-commerce value propositions founded upon the specific dimensions of: ubiquity, convenience, localization, and personalization. A consumer-orientation that provides value-for-time functions can gain a competitive advantage over traditional e-commerce models replicated for mobile business. 
New and even more innovative applications, than those discussed here, will arise as more people connect to the web through wireless devices and additional content becomes available. As other functionalities such as file attachments, faster network speeds, Bluetooth, ${ }^{10}$ speech recognition and e-commerce security features are added, more users will be attracted to this intriguing mobile marketplace. In the short-term, e-business managers must be mindful to operate within evolving technological constraints. In the end, these problems, much like the initial problems associated with e-commerce, will also be overcome.

Utilization of the appropriate value propositions will be fundamental to the success of mobile e-commerce. For m-commerce to reach its full potential of information available, anytime, anyplace and on any device, business models and strategies must offer the user maximum effectiveness and value through leveraging the unmatched advantages of wireless technology. If this is accomplished, and ecommerce business models are adapted for wireless Internet technology, expect to see a second e-business revolution take place based on the mobility of commerce.

\section{Notes}

1. Historically, most innovations suffer turbulence before the innovation prospers. Technological, social and cultural considerations may impact the rate of diffusion (Rogers, 1995). M-commerce will experience similar challenges as society adapts to these changes. Therefore, m-commerce will not be the appropriate tool for all e-commerce operations. This paper indicates that $\mathrm{m}$-commerce will best serve the organizations which can utilizes the benefits of mobility.

2. Bellman, Lohse and Johnson (1999) provide an overview of the time critical applications for online behavior.

3. Global Positioning System (GPS), Time of Arrival (TOA), Cell of Origin (COO), Enhanced Observed Time Difference (E-OTD), and Location Fixing Schemes (LFS) are just some of the completing mobile location technologies which have capabilities of providing geographic specific value-added information.

4. Issues of privacy may become a concern. Intrusive messages could alienate consumers to product/service offerings.

5. Services such as mobile AOL explore consumer profile databases to find underlying characteristics which can be used for customer service. As database marketing matures, for mobile devices, expect greater use of such utilities. 
6. SIM, or Subscriber Identification Module, refers to a smart card holding the user's identity and telephone directory. Short messaging service applications may reside within these SIMs.

7. Industry and product/service m-commerce value curves may require modification of the universal curve presented.

8. Certainly "killer apps" are rare which make them such a precious commodity. Downes and Mui (1998) explain that a "killer app" is any convergence of technologies, products and services in a way which reshapes an industry and leads to market dominance. As such, managers must scan their particular industry to find the mobile functionality which industry associates demand.

9. Managers would be wise to consider the broad range of organizational issues which may be a significant impediment to implementation.

10. Bluetooth is a chip technology that enables seamless voice and data connections between a wide range of devices through short-range digital two-way radio.

\section{References}

AlterEgo. (2000). Building the intelligent internet: Making the case for adaptive network services. Retrieved from www.alterego.com.

Albright, B. (2000). Mobilize this! Frontline Solutions, (May), 28-32.

Band, W. (2000). Creating value for your customer. Sales and Marketing Management in Canada, 31(2), 4-6.

Barnett, N., Hodges, S., \& Wilshire, M. (2000). M-commerce: An operator's manual. McKinsey Quarterly, 3, 162-171.

Bellman, S., Lohse, G. L., \& Johnson, E. J. (1999), Predictors of online buying behavior. Communications of the ACM, 42(12), 32-38.

Brandt, J. R. (2000). Dail 'm' for 'mobile'. Industry Week, (May 1), 4.

Chen, P. (2000). Broadvision delivers new frontier for e-commerce. M-commerce, (October), 25.

Daitch, J., Kamath, R., Kapoor, R., Nemiccolo, A., Sahni, J., \& Varma, S. (2000), Wireless applications for business: Business anytime, anywhere. Kellogg TechVenture 2000 Anthology, 88-120.

Datamonitor, (2000). The race for $m$-commerce: Shifting paradigms in the world of mobile commerce strategy. Retrieved from datamonitor.com. 
Downes, L., \& Mui, C. (1998). Unleashing the killer app: Digital strategies for market dominance. Boston: Harvard Business School Press.

de Haan, A. (2000). The internet goes wireless. EAI Journal, (April), 62-63.

Durlacher Research Ltd. (2000). Mobile commerce report. Retrieved from www. durlacher.com.

Evans, P. B. \& Wurster, T. S. (1997). Strategy and the new economics of information. Harvard Business Review, 75(5), 70-82.

Hoffman, G. (2000). Start game. Communications International, (April), 18-22.

Kim, W. C. \& Mauborgne, R. (1997). Value innovation: The strategic logic of high growth. Harvard Business Review, 75(1), 103-112.

Kim, W. C. \& Mauborgne, R. (1999). Creating new market space. Harvard Business Review, 77(1), 83-93.

KPMG. (2000). Creating the new wireless operator. Retrieved from www.kpmg. com.

M-commerce Times. (2000). M-commerce vital statistics, 1(16). Retrieved from www.mcommercetimes.com.

Mack, A. M. (2000). Beyond interactive to deploy wap-enabled ads. Adweek, (June 12), 59.

Mahadevan, B. (2000). Business models for internet-based e-commerce. California Management Review, 42(4), 55-69.

McGinity, M. (2000). The net/wireless meeting of the minds. Inter@ctiveWeek, (March 6), 2.

Porter, M. E. (1998). Competitive advantage: Techniques for analyzing industries and competitors. New York: The Free Press.

Rao, M. (2000). EM-wire: E-commerce, m-commerce poised for rapid take-off in Europe. Electronic Markets: The International Journal of Electronic Commerce \& Business Media, (April 6). Retrieved from www.electronicmarkets. org/electronicmarkets/electronicmarkets.nsflpages/emw_0004_cell.html.

Reed, M. (2000). Why the future will be wireless. Marketing, (February 3), 22-23.

Rogers, E. M. (1995). Diffusions of innovations (4th ed.). New York: Free Press.

Schenker. J. (2000). Europe's high-tech start-ups have stolen a march on Silicon Valley by launching new mobile services. Time Europe, (February 7), 1.

Shaffer, R. A. (2000). M-commerce: On-line selling's wireless future. Fortune, (July 10), 262.

Timmers, P. (1998). Business models for electronic markets. Electronic Markets, 8(2), 3-8. 
Zabala, H. (2000). M-commerce, the next big thing? Asian Business, (June), 34-35.

\section{Biographical Sketch of Author}

Irvine Clarke is head of the Marketing Department and Wampler-Longacre Professor of Marketing at James Madison University and a Research Fellow at the Commonwealth Information Security Center. He earned a Ph.D. from Old Dominion University in Business Administration with a major concentration in Marketing. He has published in the Journal of International Marketing, International Marketing Review, Industrial Marketing Management, and the Journal of International Consumer Marketing. He has previously taught at locations in Canada, England, France, Germany, Malaysia, Mexico, Singapore and the Peoples Republic of China. He currently serves on the Board of Advisors for assorted wireless e-commerce companies and has 15 years private sector organizational experience in technology marketing.

The author gratefully acknowledges the Commonwealth Information Security Center at James Madison University for support of their research. 
